\title{
A Designing of Google Classroom as an Online Productive Flipped Classroom Tool
}

\author{
Anurak Khophadung ${ }^{1+}$ and Pornsawan Vongtathum ${ }^{2}$ \\ ${ }^{1}$ Department of Science and Technology Education, Faculty of Education, Khon Kaen University \\ ${ }^{2}$ Department of Computer Education, Faculty of Education, Khon Kaen University
}

\begin{abstract}
Flipped classroom is an effective learning approach which promotes students' learning performances based on individual learning differences. And it focuses on educators' learning materials and knowledge tools providing to learners. This paper aims to propose a designing of Google classroom as an online flipped learning management tool for twelfth-graded students. The classroom is developed by Google which helps instructors manage their flipped classes effectively. The tools allow many functions of managing the classes and of providing applications of Google for Education. The applications for education include an online Google drive storage, documents management (Google Doc, Google Sheet and Google Slide), messages and notification of classroom activities (Gmail), and so on. The research tool was developed by the Google classroom following 5 steps of Waterfall model including requirements, design, implement, testing, and maintenance. The result shows that the flipped classroom management is depended on 4 components as follows; 1) classroom management, 2) students management, 3) learning management, and 4) students' tasks management. This kind of online classroom management concept had been reviewed and proved to be appropriate and effective by three academic experts.
\end{abstract}

Keywords: flipped classroom, Google classroom, Google for education, classroom management.

\section{Introduction}

In 21st century for education, the pedagogics approach is turned from teacher-centred into studentcentred, which means the educators are no longer transferring their knowledge to learners directly, but guiding and coaching the learners. This kind of learning will help learners get through learning, understand contents, and be able to map the knowledge themselves [1]. There is a new learning method, which is very popular in last few years, called the flipped classroom. It is a kind of blended learning methodologies which comprise of out-class and in-class schooling [2] and which focus on improving students' learning efficiency. In term of the outside-the-class study, there are learning materials, contents-based tools, and study tasks which instructors have to create and provide those learning tools for their students to help them on selflearning. The students can study the tools provided by teachers such as textbook, multimedia, and media materials anywhere and anytime outside the class whereas the in-class, the instruction is designed to help to improve learners' performances. One of effective ways to increase the performances efficiency is to implement more active instruction methodologies that make students learn by "doing", students therefore can apply their skills and knowledge to the study including solving problems, and learning collaboratively. Likewise, project-based learning allows learners to apply those skills, discuss and share their solutions.

Teachers have to implement tools for they can manage their flipped classroom easily and students can use it handily to improve their learning performances. In addition, Google designed and developed community applications for supporting online learning which can be used for creating groups from Gmail contacts (Google Groups), joining online interesting topics on Google plus (Google Communities), and

\footnotetext{
+ Corresponding author. Tel.: + 66981437879.

E-mail address: kanurak@kkumail.com.
} 
studying knowledge and information from websites (Google Site) [3]. Google also provides applications for education which are designed to help teachers and students in differentiating online learning. There are (1) Google drive: an online files storage, (2) Google Docs: a word processing tool, (3) Google Sheet: working sheets to analyse data, (4) Google Slide: a special tool for presentations, (5) Google Forms: a tool for making surveying questions, and (6) Google Classroom: the classroom management for organizing online classes [4].

Online classroom management tools are designed to allow educators manage their classes which can be used both inside class and outside class. Teachers and students are required to have an account to access to the system by signing up their emails. The google classroom allows teachers posting topics, assigning learning tasks, and questioning to the classes with ease. Students can study and turn in the assignments, and communicate with others conveniently. The assignments can be scored by the teachers with responding messages. In advance, the google classroom is designed for our integrating with third-party platforms, including student information systems (SIS) and learning management systems (LMS) [5].

According to these paradigms and technologies in education, this research is to design and develop a Google classroom for flipped classroom learning. The classroom can be used to manage outside class study and improve students' learning performances and their self-learning.

\section{Literature Review}

In this paper, there are previous theories and technologies that were already studied and analysed below.

\subsection{Flipped classroom}

Flipped classroom is a pedagogy approach which is moved from direct-learning of one class group spaces into individual learning spaces. The new learning spaces will become a more active learning in which teachers are coaches whereas students apply their knowledge concepts with engaging of creativity and problem solving in the subject matter [6]. The flipped learning paradigms comprise the study inside and outside classroom. In term of the in-class learning, the warm-up sets to the class before questioning students about the studied-contents from outside the class while rest of class activities mostly focus on active learning which help students in self-thinking and in giving more understanding by doing. Likewise, web-based instruction and social media learning can be used to improve the knowledge transferring to learners whereas in-class study, the online instruction also helps teachers design their class activities by efficiency [7].

\subsection{Google apps for education}

Recently, Google developed a solution building for teachers and students by commitment with institutions which educators can get their education emails from their school administrators supported by Google systems. The emails can be used to access every Google applications such as Gmail, and Google apps for education include Google classroom. The classroom is Google's version of an online learning management system that helps educators save time and organize classes [8]. Teachers can create online classes, distribute assignments, collect and grade the tasks with ease, send students' learning feedback, moderate discussion, and more. Students can see everything in one place, and submit their works directly. They can start the communication to the whole class or send private question to teachers as well.

\subsection{Google documents and Google drive}

Google documents [8] allow creating and editing tasks online which can be shared for working collaboratively with others invited by emails and links. The applications provide options to download in various formats including word document (Google Docs), excel supported files (Google Sheet), Power Point format (Google Slide), PDF, and more. The Google Docs is a word processing tool that teachers can create assignments attached with Google Docs materials to students. Student can access and edit it online, and turn in the work without downloading anything into their devices while Google Sheet is another document tool like the Microsoft excel that can manage categorizing data, calculating numbers, working with math module, and so on. Likewise, Google Slide is designed for making online presentations and can working in collaboration. Moreover, there is a Google Forms which is designed for making quizzes, creating surveys, collecting student information, crafting a grading rubric and much more. The result data in forms can be sent to the online sheet. Likewise, the sheet and Google documents will be stored to Google drive automatically. 
Google Drive is a productive online drive that is designed for saving and backing up any data into the clouds with providing of mobile applications. Users can upload their data to the drive, create Google documents, and make new folders. The online storage allow to edit files which are supported by google documents format, category the files folders, rename, download, delete, and share the stored files.

\section{Research Methodology}

\subsection{Experimental group}

There are 3 of academic experts in learning methodologies, technology and computer for education.

\subsection{Methodology}

This research was designed and developed the Google classroom for flipped classroom learning following 5 steps of Waterfall development model proposed by Royce (1970) [9] as shown in figure 1.

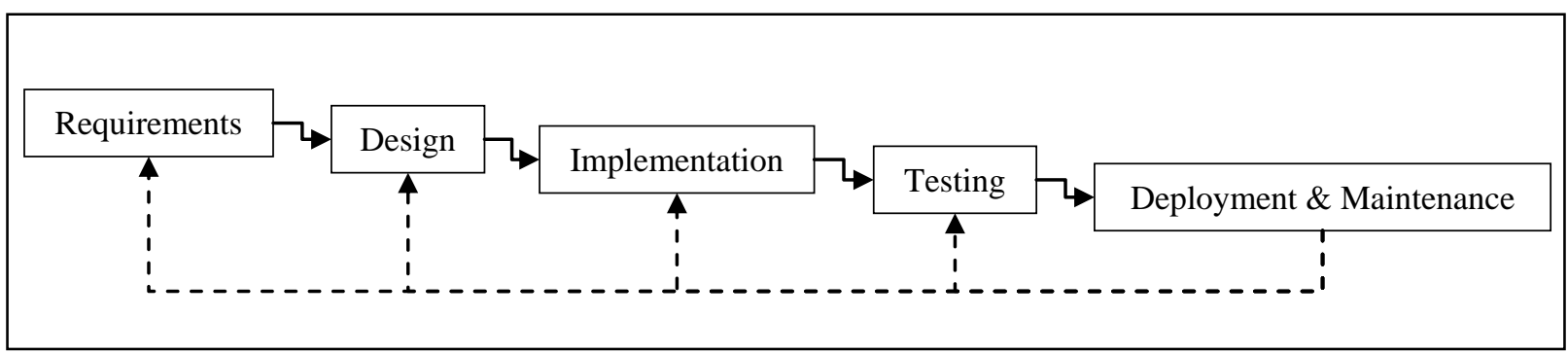

Fig. 1: Waterfall model.

- Requirements: The flipped classroom were required to improve students' learning efficiency, teachers' classroom management, and learners' outclass study. The requirements and learning theories were analyzed into the classroom management specifications.

- Design: The specifications were synthesized into the classroom management concept and designed using Google classroom with Google apps for education.

- Implementation: The flipped classroom tool was implemented on Google classroom by creating a new class. Class name and class section were required for this stage. The classroom components are classroom management, student management, learning management and students' tasks management.

- Testing: The beta online classroom had been tested and reviewed by the experts on every part of the implementation. All suggestions and guidelines to improve the Google classroom were applied. The classroom was prepared for the flipped instruction.

- Deployment and Maintenance Phase: The final Google Classroom tool for flipped classroom management, which allows teachers manage the online learning and students study and take tasks outside scheduled-classes, are deployed to the class and students are invited into this online class.

\section{Results}

The Google classroom for the flipped classroom learning had been reviewed by the group of experts appropriately and efficiently ( $\bar{X}=4.98$ ). The classroom management contained 4 components as bellow.

\subsection{Classroom management}

After the classroom was implemented, the Google Drive also was created and synced to the class for storing every data and files including learning materials and students' tasks. The classroom allows 5 functions including (1) inviting educators, (2) describing class details, (3) managing the class online storage, (4) checking class calendars, and (5) uploading learning materials. The class name, course definition and class room number were defined to provide information to students. Both the location of the class storage and the name of folders can be changed. Another teachers were invited into the class by their school emails. When the teachers accepted their invitation, they had been authorized for managing the class as well. This allows instructors of this classroom for customizing the class details, uploading main learning materials to the class, viewing the online classroom schedule via the class calendar and combining them into their google schedule via the google calendar. These classroom management is shown in figure 2(a). 


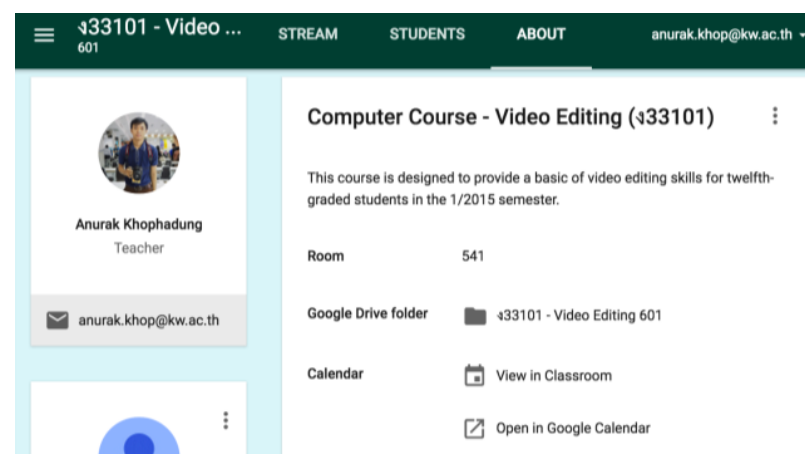

Classroom Management (a)

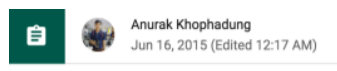

Task 5 Video Editing Software

1. Study about Corel Video Studio Pro X6 (Video Editing

2. Take an assignment "Introduction of Corel" as
3. Turn in the assignment before the deadline.

3. Turn in the
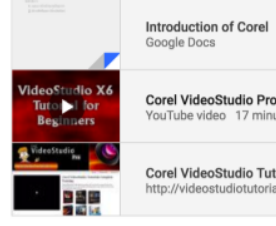
Corel Videostudio Pro X6 Tutorial for Beginners

Corel Videostudio Tutorials

6iy
Add class comment.

An Example of learning Task (c)

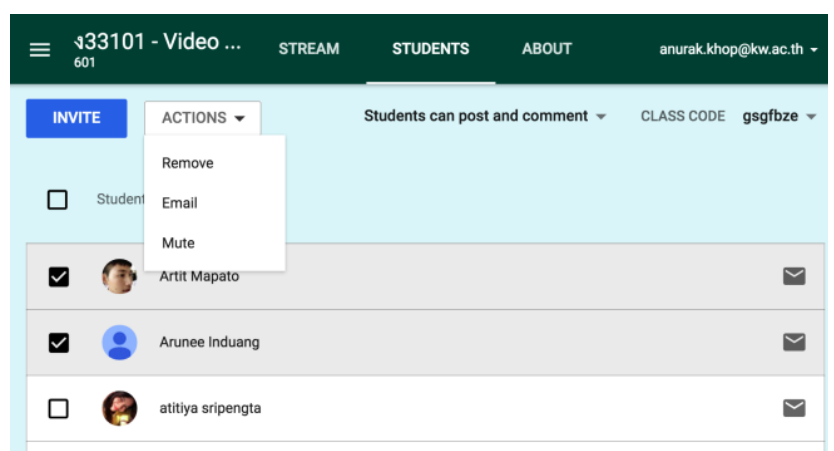

Students Management (b)
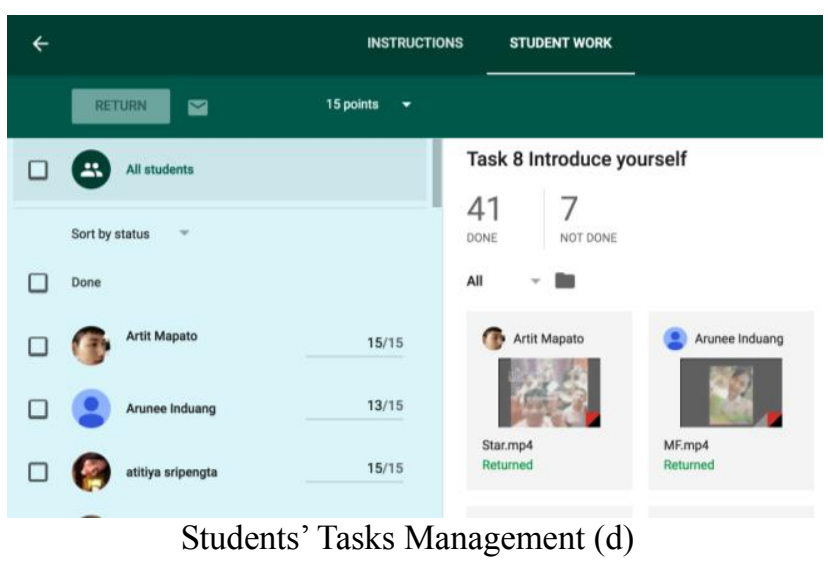

Fig. 2: Example of Google classroom screenshots.

\subsection{Students management}

Students were invited via the email which is the same as teachers' domain name and they can accepted the invitation from their mail box or joined the class from a class code. Students' privileges were managed to post and comment on this classroom. There are others 2 options as follows: (1) only teachers can post or comment, and (2) student can only comment. Teachers can send messages via email to a student or a selected students. Likewise, instructors can remove the learners who are no longer belong to this class from the Google classroom and mute them from posting or commenting in a specific class stream as well.

\subsection{Learning management}

The Google classroom were able to design learning tasks in various ways as bellows:

1) Announcement: This tool was used to announce information about the course and provided to attach uploaded files from computer, stored files in Google Drive, videos from YouTube and alternative links.

2) Assignment: This tool used to design the learning tasks by giving the tasks title, describing steps of learning guideline, defining the assignments deadline with due time, and attaching learning materials including a video demonstration, a learning media presentation, and an exercise document. The exercise was designed by Google Doc which any document types can be attached including Sheet and Slide, and was copied to each student. For another option, it can be authorized that students can view the file only or also edit the attachment file. In addition, learners would receive a notification email when the assignment was created. In term of the students' self-studies, they studied the flipped materials for understanding contents from the assignments following the guideline by studying the video materials, practicing skills from the video demo and completing their exercise. Moreover, the class assignments on stream page displayed the amount of turned-in students and amount of incompletion students. The example task is shown in figure 2(c).

3) Question: This tool allows to assign both short text and multiple choices which provided to assign questions, describe instructions, define the deadline, and determine question type. There are 2 question types which provided as follow; (1) learners can reply to each other, and (2) learners can edit their answer before the deadline. The tool would help instructors to design their out-class learning with increasing more active learning activities. Learners can improve their learning and enjoy their self-studies as a result. 
4) Reuse post: Teachers can reuse previous announcements, assignments, and questions by choosing an item from other classrooms to post to the selected classroom.

\subsection{Students' tasks management}

This management tool shown in figure 2(d) provides teachers with checking students' tasks including assignments and questions. There are displaying thumbnails of students' works with number of students with accounting by completed group and uncompleted group. It showed tasks' status when student turned it in. There are "done" status, "done late" status, and "not done" status in case of incomplete tasks. Teachers also can access the assignment's online drive by opening the greyed folder icon. The assignments' total scores were customized whereas the confirmation for entering the system was needed. If students' works were opened and scored one by one, the student had received an email notification when their work were returned with mentioning the points and comments. Likewise, students' works were returned at once if they turned the work in before the deadline, and returned one by one if they handed in their works after the deadline.

\section{Conclusion}

The classroom management provides teachers with right to control class definition and to invite other teachers to manage the class together while the student management allows all instructors to manage students and their classroom privileges. The teachers can announce various activity tasks including assignments and questions from the learning management and all students' works can be scored by the teachers using the students' tasks management with notifying points and comments to students through mailbox. In addition, the academic experts reviewed and proved the flipped tool to be appropriate and effective. The Google classroom is going to be an online productive tool and profit the online learning which meets teachers' and learners' need conventionally. This can improve the knowledge transference to students, and help them understand the contents based on individual learning differences.

\section{Acknowledgements}

This research is supported by Graduate School of Khon Kaen University (KKU) and the Promotion of Science and Mathematics Talented Teachers program (PSMT).

\section{References}

[1] A. J. Rotherham and D. Willingham. 21st Century Skills: The Challenges Ahead. Teaching for the 21st Century. 2009, 67: 16-21.

[2] V. Panich. Creating of Learning in 21 st Century. The Siam Commercial Foundation, Thailand: Bangkok, 2013.

[3] M. Renwick. (February 2016). How Google Apps Help Develop Online Learning Communities. EdTech Focus on K-12. Retrieved from http://www.edtechmagazine.com/k12/article/2016/02/how-google- apps-help-developonline-learning-communities

[4] Google Inc. (2014). Google for Education. Retrieved August 20, 2015, from https://www.google.com/edu

[5] F. Smith. (August 2015). Google Classroom API Goes Public, Giving Users More Power to Share. EdTech Focus on K-12. Retrieved from http://www.edtechmagazine.com/k12/article/2015/08/google-classroom-api-goes-publicgiving-users-more-power-share

[6] Flipped Learning Network. (March 2014). What Is Flipped Learning? The Four Pillars of F-L-I-P ${ }^{\text {TM }}$ [Online]. 2014, 1(1): 1-2. Available: http://www.flippedlearning.org/definition

[7] J. Bellanca. The 21st Century Mathematics Classroom Part II: New Models of Instruction. P21 Blogazine. [Online] 2015, 2(8). Available:http://www.p21.org/news-events/p21blog/1652-the-human-connection-in-the-21st-centurymathematics-classroom-part-ii-new-models-of-instruction

[8] D. Dykhouse, (June 2015). 5 Google Apps that Help Teachers Differentiate Instruction. EdTech Focus on K-12. Retrieved from http://www.edtechmagazine.com/k12/article/2015/06/5-google-apps-differentiate-instruction

[9] A. Mishra1, and D. Dubey. A Comparative Study of Different Software Development Life Cycle Models in Different Scenarios, International Journal of Advance Research in Computer Science and Management Studies. 2013, 1: 64-69. 